\title{
THE SCOPE OF DUE DILIGENCE IN CROSS-BORDER ACQUISITIONS IN CENTRAL AND EASTERN EUROPE
}

Alen Sacek'

University of Latvia, Riga, Latvia

\section{ABSTRACT}

Cross-border acquisitions play an important role in the corporate strategic development and international expansion. The paper summarizes the results of the dissertation, which intends to establish vital link between research and practice, deeply exploring the risk assessment methods and the scope of due diligence audit in the pre-acquisition phase. The central hypothesis of the comprehensive model stated that thorough due diligence in the pre-acquisition phase is necessary to make successfu cross-border acquisition. The empirical evidence has been drawn on data sample of acquisitions made by automotive firms in cross-border acquisitions in the Central and Eastern Europe. The main results support the proposition that the thorough due diligence audit is necessary pre-requisite for successful acquisition. The findings further support the clear trend: In the past few years, several big automotive leaders strategically gain more control over their supply chains by acquiring technology specialists. From a practical standpoint, the research results provide acquisition management with a simple method of performing the pre-acquisition evaluation of potential acquisition candidates.

\section{JEL CLASSIFICATION \& KEYWORDS}

- G32 G34 DUE DILIGENCE - EMERGING MARKETS - MERGERS AND ACQUISITIONS - RISK ASSESSMENT

\section{INTRODUCTION}

The topic of mergers \& acquisitions (M\&A) has been increasingly investigated in the literature in the last two decades in response to the rise in M\&A activities as well as the increasing complexity of such transactions themselves. In this paper the definition of M\&A will be used as acquisition, as the purchase of shares or assets on another company to achieve full managerial and operational influence. Acquiring a company abroad can be motivated by the wish of entering foreign market and establish strong position very quickly. It enables the drawing on complementary knowledge and differing market prospective of the acquired company and enables a realization of synergetic potentials (Epstein 2005). However, acquiring a company is risky when the information of the targets business is beyond the reach of acquirer and he relies on assumptions delivered by seller. At this point, an information asymmetry occurs as the acquirer does not get reliable information about the target company to carry out thorough evaluation and determine the price. In line with the literature, the term information risk is used to describe the uncertainty surrounding information relevant to the acquirer's valuations and expectations for future economic development (Gomes, Angwin, Weber, \& Tarba, 2013). The basic argument is that the firm's information environments play significant role in acquisition decision making. This seems logically, then the acquirer identifies and evaluates acquisition targets on the basis of

' alen.sacek@gmail.com

www.journals.cz their existing knowledge and the information they gain through different information search contexts Schildt \& Laamanen, 2006). This phenomenon is explained based on the information asymmetry phenomenon, which develops when the seller has more information than the buyer about the goods or services to be exchanged. Acquirer identifies and evaluates the acquisition target on the basis of existing or from the seller signalled information. On the other side, the seller needs to signal the necessary information otherwise the equilibrium cannot be established.

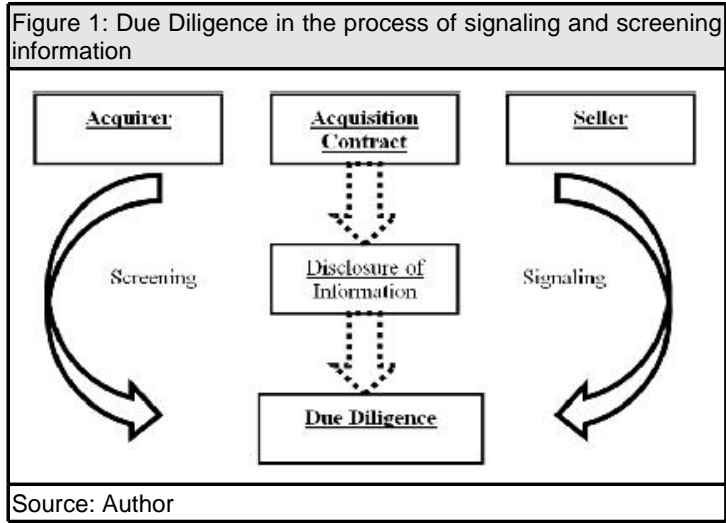

The acquirer's lack of accurate information regarding the target limits the acquisitions as combining companies can only occur when the information asymmetry can be managed. Hence, the acquirer needs to accumulate information about the target firm with screening the available information. In the acquisition process, due diligence is used to overcome the information asymmetry. The Figure 1 outlines the information flow and exchange in the context of due diligence as the tool for abolishing the information asymmetry. Due diligence comprises of detailed investigation and risk assessment in wide area of the targets specifications, either quantifiable or non quantifiable. Ideally, all information is placed in the acquisition contract which serves as the document for determining the acquisition legal framework. Due diligence in this research paper conforms to the learning theory, in particular the exploratory learning, when the acquirer learns about the target firm, it's business environment and capabilities, and country specific aspects. Such target learning process enables the reduction of the information asymmetry in cross-border acquisition.

\section{Previous research and the scope of due diligence}

In general, cross-border acquisitions and related risk assessment largely remain under-explored compared to domestic acquisitions (Bertrand \& Betschinger 2012). The previous research concentrates on the objectives of the cross-border acquisition claiming that acquisitions propose an important mechanism through which the firms grow and 
gain access to new resources. Shimizu, Hitt, Vaidyanath, \& Pisano (2004) show that market entry, learning process and value creation are among the main aims of cross-border acquisition. Similar argumentation deliver Bertrand \& Betschinger (2012) emphasizing the speed of establishing market position compared with direct investments and enables the drawing on complementary knowledge and differing market prospective of the acquired company and enable a realization of synergetic potentials.

The major channels through which the acquirers gain value are synergies, economies of scale and scope, improved efficiency and improved market access (Gomes et al. (2013). Bruner (2004) analysed 16 studies on M\&A value creating and performed interviews with 50 financial directors, but concluded that the synergies, efficiencies and value creating growth are difficult to obtain. Georgieva et al. (2012) found evidence of impact of the legal, regulatory and cultural as well as overall business environment in cross border acquisitions joint ventures. This evidence can partly be reflected to the cross-border acquisitions, as the market access is the main aim. Acquisition experience effects can occur through a firm's own acquisitions or by learning from the competitors (Barkema \& Schijven 2008). Despite the importance of due diligence and the pre-acquisition evaluation, there are not many studies which have researched the scope of due diligence, especially in case of cross-border M\&As (Schweiger \& Very 2003). There is also a lack of comprehensive study considering the full range of factors in the due diligence process (Gleich, Kierans, \& Hasselbach, 2009; Shimizu et al., 2004; Very \& Schweiger 2001).

The purpose of the paper is to show the practical use of due diligence in the pre-acquisition phase and link the extent of the due diligence with transaction success. The empirical evidence is done investigating the use of due diligence in the car manufacturing industry. In the literature study where academic and practical studies have been analysed, the characteristic fields to be assessed in the pre-acquisition phase are:

\section{Strategic and Cultural Fit}

Strategic fit of the acquisition is the degree of how the target firm's profile augments and complements strategic orientation and thus contributes identifiable to his financial and non-financial aims. The emphasis lies on the proposition that the more similar the business models and served markets and clients are, the higher the value creating effects after the acquisitions (Carbonara \& Caiazza, 2009). The importance of the strategic fit and organizational fit have even higher weigh in the context of successful cross-border acquisition (Gomes et al., 2013; Harvey \& Lusch, 1995). Angwin (2001) proved that national cultural distance affects the acquirer's perception of the target company because differences generate integration problems. Further problem fields are located in the operational environment, i.e. the IT-compatibility systems and their integration in the operational set up of the acquiring firm. The compatibility of the system is time consuming and costly and as such, an important success factor in the acquisition process.

Financial Factors and Acquisition Premium

A substantial amount of studies have identified that payment of high price premiums is one of the most significant reasons for acquisition failure, as the future growth is the main variable in determining the acquisition price (Gomes et al., 2013; Harvey \& Lusch, 1995). The main item in the risk assessment of financial positions, i.e. cash flow generation, debt volume, balance sheet leverage, asset valuation etc. (Schweiger \& Very, 2003). The effects of overvaluation of financial position bear the risk of forecasting unrealistic growth of the target firm, which may have serious effects on the valuation and the acquisition price (Perry \& Herd, 2004; Harvey \& Lusch, 1995). In line of determining realistic price, the due diligence requires enhanced proceedings to attain deeper information in order to achieve reasonable basis for evaluation models. The payment of high price premium is often that high that the synergy value of the combined unit cannot be realized. Hopkins (1999) researched this phenomenon of "synergy trap" indicating an unsuccessful acquisition.

Business Capabilities and Knowledge Management

When acquiring a foreign existing business, acquirer obtains resources like knowledge base, human resources, business capabilities and an established market access in the destination country (Schweiger \& Very, 2003) Such resources strengthen acquirer's endowment and deliver complementary resources leveraging existing resources. Their evaluation in the due diligence proceedings provide the acquirer to estimate the potential of realizing synergy effects and subsequent transaction success. In this context, human resources are considered as essential part in the realization of the synergy potentials influencing the success of the acquisition (Perry \& Herd, 2004; Schuler \& Jackson, 2011). High number of acquisitions failed when the integration of different management skills and operational skills were not identified. Knowledge is considered as one the most strategically significant resource in the organization and the combined knowledge of two firms' scales up knowledge utilization and effectiveness. In the due diligence phase, the assessment of HR potentials and knowledge potentials gives insight in quantifying the synergy potentials when successfully combined.

\section{Macro Factors and Business Environment}

The need for consideration differences in the business environment, in particular investigation legal and tax aspects of the target country has been strongly asserted as the success factor (Hitt et al., 2009) The macro-economic and corporate governance arrangements also affect the decision to acquire firms in cross border markets (Rossi \& Volpin, 2005). The nature of the local environment and its nationality (i.e. government policies, strong unions) impact acquirer's implementation practices during post-merger integration, such as changes in salary and benefits, recruiting, turnover, and labor relations. Such differences in legal and institutional environment need to be considered the risk assessment because they can lead to integration difficulties and induce further cost lowering the synergy effects (Epstein, 2005; Firstbrook, 2007).

The choice of acquisition partner according to strategic and organizational fit, the compatibility of the business capabilities and knowledge, as well as the macroeconomic factors and business environment have led to fragmented mergers and acquisitions research separating it into large research fields. Based on existing research streams as well the criticism of these streams, the model set up a comprehensive framework that integrates the research fragments (Figure 2). The intention is to develop the theoretical rationale for a comprehensive framework as well as to test the model empirically.

The dependent variable in the model is the transaction success (endogenous variable). Empirical studies mostly research the success factors from the perspective of the acquirer's owner or shareholder, as the acquisition risk 
directly impacts the financial results and pay-out ratios. The focus of the paper is the overall transaction success including the realization of the synergy effects and stand alone optimization benefits. The measurement of the variable Transaction Success is based on five different variables (Dunne \& Hodgson, 2013; Epstein, 2005):

- Synergy Value in Research \& Development, indicating the optimization of benefits in the technological competence due to the acquired firm.

- Disposal of the acquired company indicating if the acquisition's synergy effects have been realized or not.

- Overall Profitability indicating the quantitatively measurable value contribution of the acquired firm.

- Return on Investment indicating the linear relation of return on invested capital.

- Overall Success of the acquisition is a qualitative measure indicating the acquirer's judgment about the firm's either intangible or tangible contribution to combined success.

In wake of the richness of factors, the research design has been constructed with structural equation modeling (SEM) as a multivariate data analysis method that is often used when testing theoretically supported linear and additive causal models. The criteria for the use of PLS model, which is a variance based model, are: small sample size with $n=$ 52 , the independent variables are normally distributed (univariate approach) and the research paper has cause effect research character. PLS is useful for structural equation modeling in applied research projects especially when there are limited participants and that the data distribution is skewed and this is the case in the survey (Hair, Ringle, \& Sarstedt, 2012; Sarstedt \& Ringle, 2011).

In the present research model, the inner model explains if the dependent variable performance (Transaction Success) is influenced by the independent latent variables previously described: Strategic and organizational fit, Business capabilities and knowledge management, Financial factors and acquisition premium, and macro-economic factors and business environment (exogeneous variables). However the independent variables are not directly observable and therefore, they are explained by 19 manifest variables that have been derived from the literature review. Graphically summed up, the research framework can be established as follows:

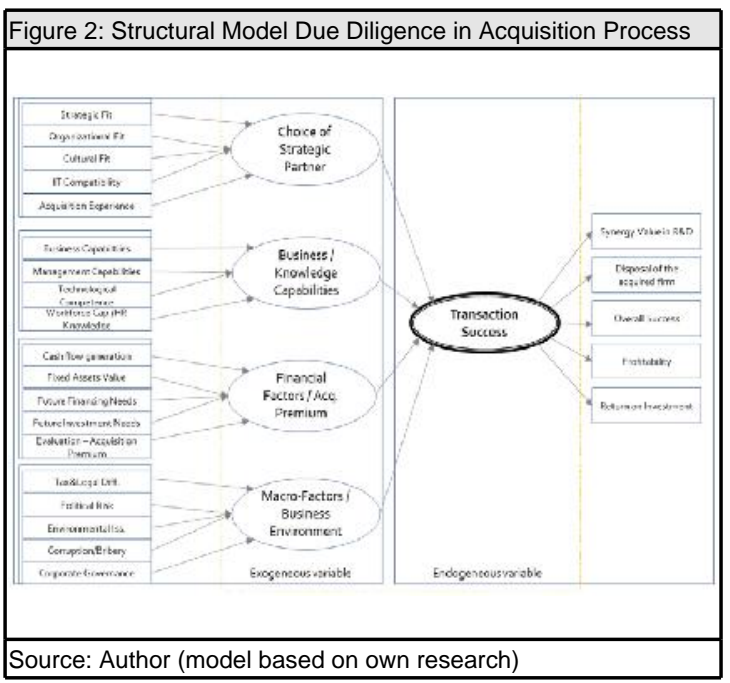

www.journals.cz
The inner model consists of the four main hypothesis including elements of thorough due diligence and the transaction success. The outer model consists of manifest and independent variables and the dependent variables which explain the transaction success.

\section{Empirical Results}

The empirical research was performed with questionnaire survey collecting data from a sample of German automotive industry involved in cross-border acquisitions between 2007 and 2013 in the Central and Eastern European region. A list of the finalized deals was compiled from the Merger market Database and complemented by Thomson Financial data. The sample consists of 52 evaluated transactions in the cross-border acquisitions. This represents ca. $34 \%$ of the full population $(\mathrm{N}=155)$ in the automotive industry and geographical region. The reliability of the survey was supplemented by pre-testing of the questionnaire with independent industrial experts.

With SEM, the relationship between multifaceted risk factors in the due diligence and the transaction success model is being operationalized with formative measurement model. The reliability and predictive relevance is being judged using Stone-Geisser criteria and additionally with the coefficient of determination. With the coefficient of determination of 0.69 , and the predictive estimation with 0.35 the model shows high usefulness. In the operationalization of the reflexive measurement model (endogenous variable), the construct Transaction Success shows good average variance extracted (AVE; 0.6) very good discriminant validity and with 0.897 very good construct reliability. In terms of Fornell-Larcker Criterion, the square root of the AVE is compared with correlations of the independent constructs with the dependent construct Transaction Success. The 0.77 shows that this criterion is fulfilled.

Having selected the variables, the results of the relationships are visualized in Figure 3. Premium" have strong influence on the latent variable "Transaction Success". The variable "Macro-Factors and Business Environment" has a middle strong influence on the latent variable "Transaction Success". The construct "Choice of Strategic Partner" is non-significant and does not have influence on the independent variable.

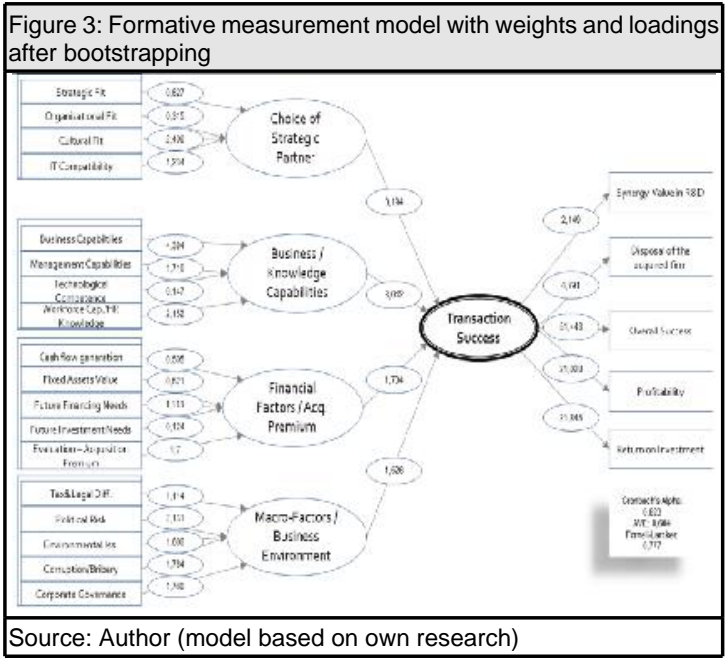

In Table 1, the formative measurement model the importance of employee capabilities and business capabilities as a factors contributing to the success of 
acquisitions were proved and the findings in the prior research has been confirmed (Bruner, 2004; Hitt et al., 2009). Especially the high significance of human resources factors supports the prior research findings in that the firms acquiring innovation capabilities are keen to identify intellectual capital and knowledge The factor concerning the management competence has been proven non significant which is partially contrary to prior research suggesting the important management role in the post integration phase. The newer research supports focussing more on Business Capabilities than on capabilities on the management level. The weigh in the model has been negative indicating the negative influence of not taking care of the justifiable acquisition price level. The high value in the acquisition premium can be explained by the use of market based measures of valuation. Such a valuation derives the value what other comparable companies are worth or what recent comparable acquisition transactions have traded for. In such cases the acquisition price overwhelms the intrinsic value that is based on what a firm is worth in the sum-of-the-parts approach. The indicators "Cash flow Generation", "Fixed Assets Value" show only weak significance, indicating that the overall financial picture needs to be taken into account. The "Future Financing Need", an indicator measuring the self-financing capacity of the target firm's business model seems not to have important role by the acquirer. This seems logical, as the survey acquirer are established international market players with high capital access possibilities. The indicator "Future Investment Needs" is significant indicating the role of synergy realization in the post-acquisition phase. Consequently, the acquirer evaluates the needs in order to estimates the capital expenditure in order to examine the impact of the value enhancement by the new combination. However, as the three indicators do not play an important role, there is sign at this stage that the SEM has need for further improvement. While the indictor Strategic Fit shows acceptable significance, other variables of the Construct "Choice of Strategic Partner" have low significance and this is completely against the leading research findings. Also on this there might be an improvement need for the SEM.

In the field of Macro-Factors and Business Environment, there is a high importance for the acquirer to measure and evaluate the macroeconomic indicators and the political stability of the target firm's origin country. A bid weaker, but still important is the Corporate Governance including the Bribery/Corruption risk which may negatively impact the image of internationally oriented company's image.

The path coefficients of the constructs "Business Capabilities and Knowledge Management" and "Macro Factors and Business Environment" are significantly different from 0 and suggest positive predictability characteristic for the latent variable "Transaction Success" in the structural model. Considering the t-values, the variables "Business Capabilities and Knowledge Management" and "Financial Factors and Acquisition Premium" have strong influence on the latent variable "Transaction Success". The variable "Macro-Factors and Business Environment" has a middle strong influence on the latent variable "Transaction Success". The construct "Choice of Strategic Partner" is non-significant and does not have influence on the independent variable. This is completely against the leading research findings. Also on this there might be an improvement need for the SEM.

The central proposition is that complete due diligence scope in the pre-acquisition phase is necessary to make

\begin{tabular}{|l|l|l|l|l|}
\hline Table 1: Table Coefficients and the significance of the Constructs \\
\hline $\begin{array}{l}\text { Constructs- } \\
\text { independent } \\
\text { variables }\end{array}$ & Path Coefficient & $\mathbf{t}$-values & $\mathbf{p}$-values & VIF \\
\hline $\begin{array}{l}\text { Choice of } \\
\text { Strategic } \\
\text { Partner }\end{array}$ & 0,115 & 1,187 & 0,236 & 1,269 \\
\hline $\begin{array}{l}\text { Business } \\
\text { Capabilities and } \\
\text { Knowledge } \\
\text { Management }\end{array}$ & 0,301 & 2,414 & 0,016 & 1,150 \\
\hline $\begin{array}{l}\text { Financial } \\
\text { Factors and } \\
\text { Acquisition } \\
\text { Premium }\end{array}$ & $-0,468$ & 3,625 & 0,000 & 1,436 \\
\hline $\begin{array}{l}\text { Macro Factors } \\
\text { and Business } \\
\text { Environment }\end{array}$ & 0,282 & 2,114 & 0,035 & 1,158 \\
\hline
\end{tabular}

successful cross-border acquisition. Consequently, statistical methods of outer model analysis and inner model analysis were utilized to test the proposition. In the framework, the main proposition, three of four constructs were proved significant in relation to the transaction success. The significant impact was proven in the both, the inner and outer model analysis. Summed up, the results show:

\begin{tabular}{|c|c|c|}
\hline Constructs & & Significance \\
\hline 0 & $\begin{array}{l}\text { Thorough due diligence in the } \\
\text { pre-acquisition phase }\end{array}$ & *** \\
\hline 1 & Choice of Strategic Partner & n.s. \\
\hline 2 & $\begin{array}{l}\text { Business Capabilities and } \\
\text { Knowledge Management }\end{array}$ & *** \\
\hline 3 & $\begin{array}{l}\text { Financial Factors and } \\
\text { Acquisition Premium }\end{array}$ & ** \\
\hline 4 & $\begin{array}{l}\text { Macro Factors and Business } \\
\text { Environment }\end{array}$ & ** \\
\hline
\end{tabular}

When analyzing the data from the learning perspective, the findings indicate that the problems of collecting reliable information and determining the fair value for the target firms are the main challenge of decision makers in the preacquisition phase (exploratory learning). On the other side, the problematic in such a case may be when the acquirer does not have any experience in cross-border acquisition or in the acquisition practice at all (experience accumulation process). On the level of exploratory learning, the due diligence process solves the problem of collecting reliable information, when the scope includes detailed evaluation of Business Capabilities and the Financial Factors (especially the determination of the Acquisition Premium). The findings support this organizational learning factor and its role in balancing information asymmetry and suggest, the more information the firms analyzes in the pre-acquisition phase, the more better the foundation for due diligence. The problem is concentrated on acquiring and interpreting information about the target to fairly evaluate and price the transaction. In other words, the findings suggest the more the firm learns about the target in the due diligence audit, the better will be the cross-border acquisition success. The second outcome through the lens of the organizational learning theory is the repetitive factor of the acquisition process and the pre-acquisition evaluation which leads to experience accumulation that can be used in the future acquisitions. 


\section{CONCLUSION}

The literature research shows no comprehensive study which considers the full range of factors to be considered in pre-acquisition evaluation within the due diligence process. The contributed development of a model incorporating different risk areas delivers theoretical implications in the field of risk assessment in cross-border acquisition management. The linkage between the organizational exploratory learning and removing information asymmetry has been proven. The results of the tested model indicate that there is a positive relationship between successful acquisition and appropriate scope of due diligence proceedings. The main result lies in pinpointing the specific area by which the business capabilities and knowledge transfer build the main asset in the realization of synergy values in the acquisition phase. In this context, the valuation of the business capabilities of the acquisition targets can be classified as the main challenge reflecting suitability of the acquisition price.

The managerial implications are that in the pre-acquisition phase the due diligence proceedings should selectively be audited especially in case of evaluating business knowledge capabilities. The determined low importance of strategic, cultural and organizational fit, which is usually one of the most named aspects in transaction success, is indeed surprising. However, the strategic focus of the German automotive firms is to capture capable contributor in the manufacturing chain and deepen the technological knowledge of the overall enterprise. The motive for vertical integration of operations along the chain value implies the exercise of market power. The cost pressure forces automotive industry to maximize joint surplus, up and downstream of the chain value, as this maximizes its profits and increases the competitiveness.

The tested financial issues go beyond the information provided and this will provide the basis for forecasting future performance and identifying possible capital short falls has been supported moderately for the German acquirers in the car manufacturing industry. The high impact of acquisition premium on transaction success but the obvious low importance of other financial indicators for survey participants is not logical but supports research results (Gomes et al., 2013) concluding that acquirers tend to be driven by prices of comparable acquisitions, rather than assessing relevant risks in the valuation and price building phase.

In line with that, the identification of the most efficient tax and legal structure is not significant aspect for German car manufacturer. The reason may lie in the financial power and good access to capital market of the globally active companies which can offset such potential burdens. Afterwards, such evaluated risks are reflected in the acquisition price which help to ensure that the M\&As dea intelligence gets wider scope of the risk assessment methods and finally improve the success rates in cross border acquisitions.

The limitation of the research is the small sample and the narrowing effect of the industry limitation. Moreover, the limitation to German based firms may not represent the best practice of international companies. Considering further primary data and broader sample could lead to more complex analysis, contributing more confidence in the findings. The broad questionnaire and the limited availability of the senior executives do not allow broader participants base. As in most academic studies with empirical results in mergers and acquisitions, the high obligation for confidentiality hinder thorough research of the topic.

www.journals.cz

\section{REFERENCES}

Ahammad, M. F., \& Glaister, K. W. (2013). The pre-acquisition evaluation of target firms and cross border acquisition performance.

International Business Review, 22, 894-904.

Angwin, D. (2001). Mergers and Acquisitiosn across European Borders: National Perspectives on Preacquisition Due Diligence and the Use of Professional Advisers. Journal of World Business, 36(1), 32-57

Barkema, H. G., \& Schijven, M. (2008). How Do Firms Learn to Make Acquisitions? A Review of Past Research and an Agenda for the Future. Journal of Management, 34(3), 594-634.

Bertrand, O., \& Betschinger, M.-A. (2012). Performance of domestic and cross-border acquisitions: Empirical evidence from Russian acquirers. Journal of Comparative Economics, 40(3), 413-437.

Bruner, R. F. (2004). Does M\&A Pay - A Survey of Evidence for the Decision-Maker. Journal of Applied Finance, 12(1), 48-68.

Carbonara, G., \& Caiazza, R. (2009). Factors Affecting M \& A Success: A Starting Point for the Topic Renaissance. The Journal of American Academy of Business, 15(Sept), 92-99.

Dunne, P., \& Hodgson, A. (2013). M \& A Deal Evaluation: Challenging Metrics Myths. London.

Epstein, M. J. (2005). The Determinants and Evaluation of Merger Success. Business Horizons, 48(1), 37-46.

Firstbrook, C. (2007). Transnational Mergers and Acquisitions: How to Beat the Odds of Disaster. Journal of Business Strategy, 28(1), $53-56$.

Georgieva, D., Jandik, T., \& Lee, W. Y. (2012). The impact of laws, regulations, and culture on cross-border joint ventures. Journal of International Financial Markets, Institutions and Money, 22(4), 774795.

Gleich, R., Kierans, G., \& Hasselbach, T. (2009). Value in Due Diligence. Gower Publishing.

Gomes, E., Angwin, D. N., Weber, Y., \& Tarba, S. (2013). Critical Success Factors through the Mergers and Acquisitions Process Revealing Pre- and Post-M \& A Connections for Improved Performance By. Thunderbird International Business Review 2 55(1), 13-35.

Graham, M., Martey, E., \& Yawson, A. (2008). Acquisitions from UK firms into emerging markets. Global Finance Journal, 19(1), 56-71.

Hair, J. F., Ringle, C. M., \& Sarstedt, M. (2011). PLS-SEM: Indeed a Silver Bullet. The Journal of Marketing Theory and Practice, 19(2), 139-152.

Harvey, M., Lusch, R. (1995). Expanding the Nature and Scope of Due Diligence. Journal of Business Venturing, 9026(10), 5-21.

Hitt, M. A., King, D., Krishnan, H., Makri, M., Schijven, M., Shimizu K., \& Zhu, H. (2009). Mergers and acquisitions: Overcoming pitfalls, building synergy, and creating value. Business Horizons, 52(6), 523-529.

Hopkins, H. D. (1999). Cross-border Mergers and Acquisitions: Global and Regional Perspectives. Journal of International Management, 5(3), 207-239.

Jemison, D., Sitkin, S. (1986). Corporate Acquisitions: A Process Perspective. Academy of Management, 11(1), 145-163.

Knecht, F., \& Calenbuhr, V. (2007). Using capital transaction due diligence to demonstrate CSR assessment in practice. Corporate Governance, 7(4), 423-433.

Perry, J. S., \& Herd, T. J. (2004). Mergers and Acquisitions: Reducing M\&A risk through improved due diligence. Strategy \& Leadership, 32(2), 12-19.

Rossi, S., \& Volpin, P. F. (2004). Cross-country determinants of mergers and acquisitions. Journal of Financial Economics, 74(2), 277-304.

Sarstedt,M., \& Ringle, C. M. (2011). Multigroup Analysis in Partical Least Squares (PLS) Path Modeling:

Alternative Methods and Empirical Results. Measurement and Reasearch Methods in International Marketing, 22, 195-218. 
Schildt \& Laamanen, T. (2006). Who buys whom: Information environments and organizational boundary spanning through acquisitions. Strategic Organization, 4, 111-133.

Schuler, R., \& Jackson, S. (2001). HR Issues and Activities in Mergers and Acquisitions. European Management Journal, 19(3), 239-253.

Schweiger, D.M. \& Very, P. (2003). Creating Value through Merger and Acquisition Integration. Advances in Mergers and Acquisitions, 2, 1-26.

Shimizu, K., Hitt, M. A, Vaidyanath, D., \& Pisano, V. (2004). Theoretical foundations of cross-border mergers and acquisitions: A review of current research and recommendations for the future. Journal of International Management, 10, 307-353.

Very, P., \& Schweiger, D. M. (2001). The Acquisition Process as a Learning Process: Evidence from a Study of Critical Problems and Solutions In Domestic and Cross-Border Philippe Very. Journal of World Business, 36(1), 11-31. 